\title{
STUDENTS' LEARNING STYLES AND PREFERENCES IN LEARNING SELECTED STATISTICAL TOPICS BASED ON INTERVIEW AND MULTIDIMENSIONAL SCALING TECHNIQUE
}

\author{
Zamalia Mahmud ${ }^{1}$, Nurulasyikin Mohd Ibrahim ${ }^{2}$, Shamsiah Sapri ${ }^{3}$, Sanizah Ahmad ${ }^{4}$ \\ 1,2,3,4 Faculty of Computer and Mathematical Sciences, Universiti Teknologi MARA, Selangor, \\ Malaysia \\ 'zamalia@tmsk.uitm.edu.my, ${ }^{2}$ nurulasyikin2505@gmail.com, ${ }^{3}$ sanizah@tmsk.uitm.edu.my, \\ shamsiah@tmsk.uitm.edu.my
}

\begin{abstract}
Students very often perceive statistics as a difficult subject to learn and have generally shown very little interest in it much to the dismay of educationists and instructors alike. This study investigates the problems students face when learning certain statistical topics by firstly relating these learning difficulties with the effort put in when understanding the topics. This is followed by categorizing students' learning styles and preferences based on Kolb's Learning Model. Phase 1 explores these levels of learning difficulty, while Phase 2, the case study of 22 students, further investigates the students' learning styles. The analysis is based on a content matrix of students' learning of statistical topics using Kolb's Learning Model, Qualitative Data Analysis (QDA) and Multidimensional Scaling. The study results indicate that learning difficulties can be overcome by employing different learning styles. The majority of the students fall into the 'Converging' category as they prefer to do practice exercises and study on their own. A small number of students fall into the 'Accommodating' and 'Diverging' group, as they prefer to study in small groups and consult lecturers when the need arises. Finally, an even smaller number comes under the 'Assimilating' group as they prefer to read textbooks and look up for notes from other sources from the internet. Other factors such as prior knowledge in statistics, ability to work with statistics and personal effort are also found to support students' interest in learning statistics.
\end{abstract}

Keywords: Learning Difficulties, Learning Styles, Kolb's Learning Model, Qualitative Data Analysis (QDA) and Multidimensional Scaling (MDS).

\section{INTRODUCTION}

Statistics and probability are two essential topics often required in many academic disciplines, but somehow learning them at all education levels seems to be a daunting task for many students. In some way, this difficulty has led to the perception that the discipline is complex, its statistical methods tough and its range of topics unexciting for classroom learning (Garfield and Ben-Zvi, 2004).

Many students and educators also do not realize that many aspects of statistics can be learnt and understood in many different ways. In a normal classroom situation, instructors tend to give authority to the students to select their own preferred learning style in order to promote not only self-awareness of their chosen strategies, but also their practical applications in an actual learning environment (Tanner and Allen, 
2004). Furthermore, each student has a different way of receiving, retrieving and retaining information from different perspectives as well as different levels of understanding the subject matter. A good knowledge of students' learning styles could help instructors improvise teaching methods in order to help students overcome some of their difficulties in learning statistics. Also, when students recognize their own learning styles, they can be more positive about using these preferred ways to complete tasks in ways that satisfy their needs (Reid, 2005). Hence, this study has been conducted to investigate the various categories of students' learning styles and preferences for the purpose of overcoming difficulties in learning statistics.

\subsection{Research Questions}

This study sets out to answer the following research questions:

- Why do students find difficulties in learning statistics?

- Which statistical topics do students find difficulty in understanding?

-What are some of the efforts made by students who have difficulties in learning statistics?

-What are the categories of students' learning styles and preferences?

\section{LITERATURE REVIEW}

\subsection{Learning Statistics}

Students in Malaysia are first exposed to the study of statistics at the age of nine. It is taught at both the elementary and secondary education up to the age of 17 . When students reach A-Level Mathematics, they are taught more advanced statistical topics such as probability and inferential statistics (Ministry of Education Malaysia, 2006).

Before going into the actual process of learning statistics, it is important to look at how students learn in general (Garfield, 1995). Basically, learning refers to knowing something. Tsai and Kuo (2008) found that students' willingness to learn halted a fear of getting low marks and they define learning as memorizing information, preparing for tests, solving problems and calculating.

Although there is no definite definition of learning, undergoing that process can be within the individual itself or within a group of students. However, a generally accepted definition of learning is any relatively permanent change in behavior that occurs as a result of experience (Robbin, 1998).

According to Schau, Millar and Petocz (2012), it is becoming increasingly apparent that attitudes exert a primary impact on students' academic behaviors in statistics education. Zamalia and Nor Hasmaniza (2010) stated that students attributed their positive change towards learning introductory statistics after they have gone through extensive learning of the topics in the class. Nooriafshar (2003) also illustrated the positive response from students as extremely rewarding after mastering the statistical concepts

\subsection{Learning Style and Preference}

There are various theories that can be used to clarify and classify learning styles preferred by an individual. Most of the methods used to categorize students' learning style focuses on environmental preferences, sensory modalities, personality types, and/or cognitive styles (Romanelli, Bird and Ryan, 2009). It is known that learning styles are not fixed and stationary because students learn differently. Every student possesses their own learning style depending on the subject being learnt and the learning environment. Christou and Dinov (2010) define learning style as an individual's approach to responding to new learning stimuli.

There are several theories defined on the learning process of students. Kolb (1984) originally categorized learning styles into accommodating, diverging, converging, and assimilating. Chapman (2006) then improvised the model based on four common characteristics of human which is learning by watching, thinking, feeling and doing. These are used together to effectively identify student learning styles and preferences.

\section{METHODOLOGY}

\subsection{Study design}

This study adopts a mixed mode research design which involves the use of both qualitative and quantitative methods (Creswell, Klassen, Clark and Smith, 2010). Phase 1 of the study is exploratory and identifies statistical topics that students find difficult to understand, including their different levels of difficulty. Phase 2 is a case study of 22 students which involves an in-depth investigation of their learning styles. 


\section{Learning Styles and Cross Matrix Table}

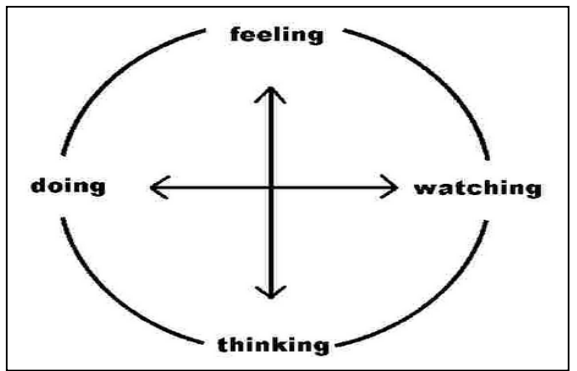

Figure 1. Kolb's Learning Model Chart

Kolb's Learning Model (Fig. 1) was used to identify the categories of students' learning styles and preferences when learning statistics. To facilitate categorization of these preferred styles, the students were asked the following questions:

- How do you first approach a task?

- What is your emotional response to the experience?

The example illustrates the placement of learning styles according to the categories suggested in Kolb's Learning Model. Students choose their approach to a task or experience by watching others involved in the experience and reflecting on what happen ('watching') or by 'jumping straight in' and just doing the task straightaway ('doing'). To emotionally transform the experience into something meaningful and useful means to gain new information from thinking, analyzing, or planning ('thinking') or to experience the 'concrete, tangible, felt qualities of the world' ('feeling').

Their responses to the questions were then tabulated and categorized according to four possible combinations, namely watch-think, watch-feel, do-think and do-feel (Chapman, 2006). These combinations were then cross-tabulated based on each student's response as shown in Table 1.

Table 1. Two-by-Two Matrix of Students' Learning Styles and Preferences Based on Kolb's Learning Model (Chapman, 2006)

\begin{tabular}{|c|c|c|}
\hline & Doing (Active Experimentation - AE) & $\begin{array}{c}\text { Watching (Reflective } \\
\text { Observation - RO) }\end{array}$ \\
\hline Feeling (Concrete Experience - CE) & Accommodating (CE/AE) & Diverging (CE/RO) \\
\hline $\begin{array}{c}\text { Thinking (Abstract Conceptualization - } \\
\text { AC) }\end{array}$ & Converging (AC/AE) & Assimilating (AC/RO) \\
\hline
\end{tabular}

\subsection{Qualitative Data Analysis (QDA)}

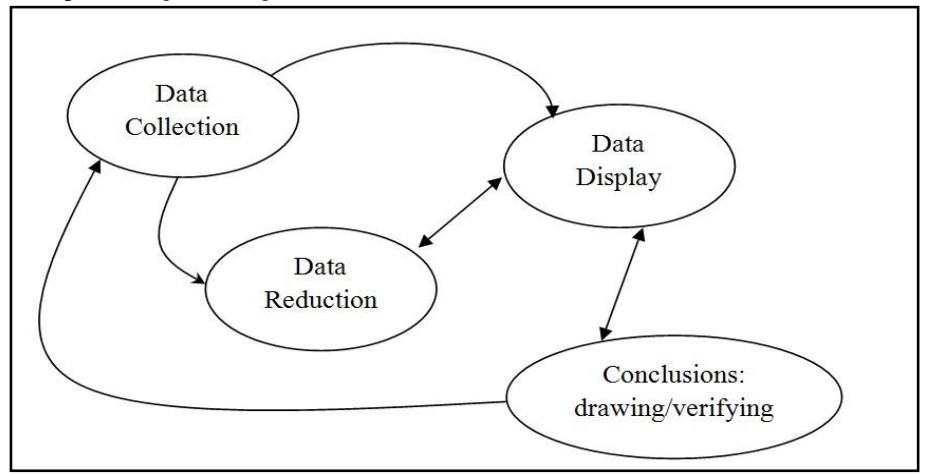

Figure 2. Components of data analysis: interactive model (Miles and Huberman, 1994).

Fig. 2 shows the steps involved in processing qualitative data. It displays the process of QDA in getting information from the conversations and in forming the data. The medium of data collection for QDA is via the interview method. 


\subsection{Multidimensional Scaling (MDS)}

According to Hair, Black and Babin (2010), Multidimensional Scaling (MDS) is known as perceptual mapping. Therefore, the Euclidean method is used to measure the distance by most researchers. This is because the Euclidean distance is the well-known method in the MDS (Borg, Groenen and Mair (2012). Thus, the Euclidean distance measure formula is given as:

$$
\sqrt{\sum_{k}\left(x_{k}-y_{k}\right)^{2}}
$$

\subsubsection{Assessing Fit of Multidimensional Scaling (MDS)}

Johnson and Wichern (2002) explain that the stress value should be as small as possible. Kruskal and Wish (1978) suggests that the stress to be informally interpreted according to few guidelines where he measure goodness of fit is by referring to relationship between the similarities and the final distances. A stress value less than 0.10 indicates the configuration of objects to be considered reliable (Quinn and Keough, 2002). It also indicates an acceptable fit between the original proximities and the derived distances. The formula of the Stress-I is given as:

$$
\text { Stress }-I=\sqrt{\sum_{i<j}\left(d_{i j}(X)-\hat{d}_{i j}\right)^{2} / \sum_{i<j} d_{i j}^{2}(X)}
$$

According to Borg, Groenen and Mair (2012), the Shepard diagram is the measure of closeness of the regression trend. If the data approximate a straight-line relationship with minimal dispersion, this indicates that the original proximities are represented well as distances in a multidimensional space and can interpret the configuration of MDS solution. The Shepard diagram is further evidence of the reasonably high level of fit between the transformed proximities and derived distances.

\subsubsection{Interpretation of MDS}

There are two things to look for in the interpretation of an MDS picture: clusters and dimensions. Clusters are groups of items that are closer to each other than to other items. The underlying dimensions are thought to explain the perceived similarity between items (Kruskal and Wish, 1978).

\section{DATA ANALYSIS AND RESULTS}

\subsection{Phase 1: Difficult Topics}

The majority of students $(75.7 \%)$ found that the topic related to Poisson approximation to the Binomial distribution as most difficult to learn. This is followed by the Binomial distribution topic at $73.8 \%$ and Poisson distribution at $69.9 \%$, both of which are considered as moderately difficult. Based on Phase 1 results, an indepth investigation was conducted to identify the students' learning styles and their experience in learning difficult topics.

\subsection{Phase 2: In depth Investigation of Learning Styles Using Interview Analysis and Multidimensional Scaling}

The in depth investigation of learning styles using the interview technique was conducted on 22 students.

\subsubsection{Kolb's Learning Chart and Cross Matrix Analysis}

Table 2 below demonstrates the majority of the students' preference for learning new topics by thinking and doing relevant exercises or by solving problems in the class, while a small number of others prefer to watch and think about the problems instead. Based on Kolb's Learning Model, the majority of these students could be considered as having a "converging" learning style. This refers to the combination of grasping and transforming experience. People who possess this style are thought to have a rather dominant learning style as it is about 'doing' rather than 'watching' the task and 'thinking' rather than 'feeling' about the experience. People with this learning style are also considered capable of solving problems and using their learning to find solutions to practical issues. 
Table 2. Characteristics of learning style based on Kolb's Learning Model

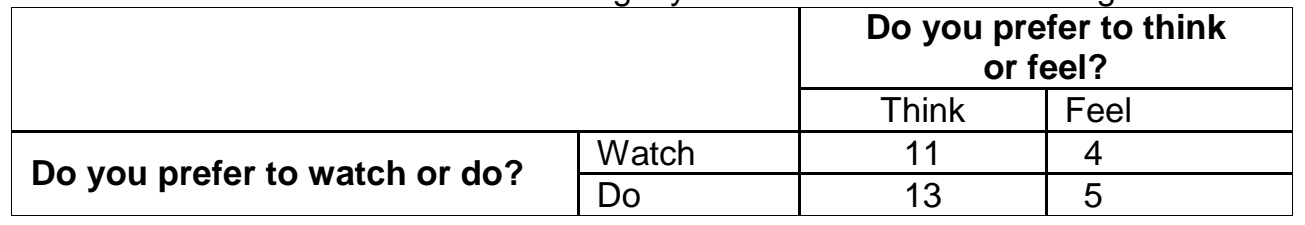

\subsubsection{Qualitative Data Analysis (QDA) of Interview Data}

The interview identified eight prevailing themes. The first five themes were categorized and coded according to the responses given to these questions: "Why do you find it difficult to learn these topics? and "What are your preferred learning styles and efforts in understanding these topics?" There were some similarities in the answers provided by the students even though the structure of their answers was different. The themes were then categorized and coded accordingly.

This led to the construction of two sets of ' $22 \times 2$ ' matrix display of interview conversation comprising five (5) themes and 2-dimensional codes associated with the student responses. There was also an ' $11 \times 2$ ' matrix display of interview conversation comprising three (3) themes and 2-dimensional codes. Excerpts of the interview conversation matrix display are shown in Tables 3 and 4.

Table 3. Excerpts of interview conversations showing the themes and codes relating to learning difficulties

\begin{tabular}{|c|c|}
\hline Students & Reasons for difficulties in learning statistical concepts \\
\hline Student 6 & $\begin{array}{l}\text { COMP: Need a calculation to get the numerical answer and no basis of } \\
\text { understanding. Then, I think that statistics is all about calculation. } \\
\text { ATT: Cannot focus in class and do not like this subject } \\
\text { THEO: Do not know how to differentiate the conditions of binomial and poisson } \\
\text { distribution and the formula that needs to be used. }\end{array}$ \\
\hline Student 22 & $\begin{array}{l}\text { THEO: A lot of procedures and steps must be remembered and understood. Then, } \\
\text { I cannot notice the formula of probability. } \\
\text { ABLE: Could not think through the problem on my own and needed reference as a } \\
\text { guide to doing it. Other than that, I don't really understand the concept and tend to } \\
\text { learn by rote. } \\
\text { PKNOW: This is the first statistical concept that I have met. }\end{array}$ \\
\hline Student 15 & $\begin{array}{l}\text { COMP: Got confused to calculate and to arrive at getting the numerical answer } \\
\text { quickly. } \\
\text { ATT: Understand it only in class, then after class I forgot what I have learnt. } \\
\text { ABLE: Unable to think through the problems on my own. } \\
\text { PKNOW: I think this subject is an extension of mathematics. Then, I have the } \\
\text { objective of getting a numerical number rather than understanding it. }\end{array}$ \\
\hline
\end{tabular}

Table 4. Frequency of themes mentioned by students during the interview

\begin{tabular}{|c|c|c|c|}
\hline Theme Codes & Codes description & $\begin{array}{c}\text { Frequency of themes } \\
\text { mentioned }\end{array}$ & Percentage (\%) \\
\hline ABLE & Ability & 14 & 24.6 \\
\hline THEO & Theory & 18 & 31.6 \\
\hline PKOW & Prior Knowledge & 8 & 14.0 \\
\hline ATT & Attitude & 10 & 17.5 \\
\hline COMP & Computation & 7 & 12.3 \\
\hline
\end{tabular}

\subsubsection{Assessing Fit of Multidimensional Scaling (MDS)}

Table 5 shows the Kruskal's Stress-I value in order to assess fit of the MDS. The Kruskal Stress-I values for the MDS solutions are less than 0.10 indicating an acceptable fit between the original proximities and the derived distances. 
Table 5. The Stress-I or Kruskal's Stress value for MDS solutions

\begin{tabular}{|l|c|}
\hline \multicolumn{1}{|c|}{ MDS Solutions } & $\begin{array}{c}\text { Kruskal } \\
\text { Stress-I }\end{array}$ \\
\hline Students' Learning Difficulties and Their Effort in Understanding Topics & 0.06434 \\
\hline \multicolumn{1}{|c|}{$\begin{array}{l}\text { Students' Learning Styles and Preferences Based on Kolb's Learning Model and Their } \\
\text { Effort in Understanding Topics }\end{array}$} & 0.02777 \\
\hline
\end{tabular}

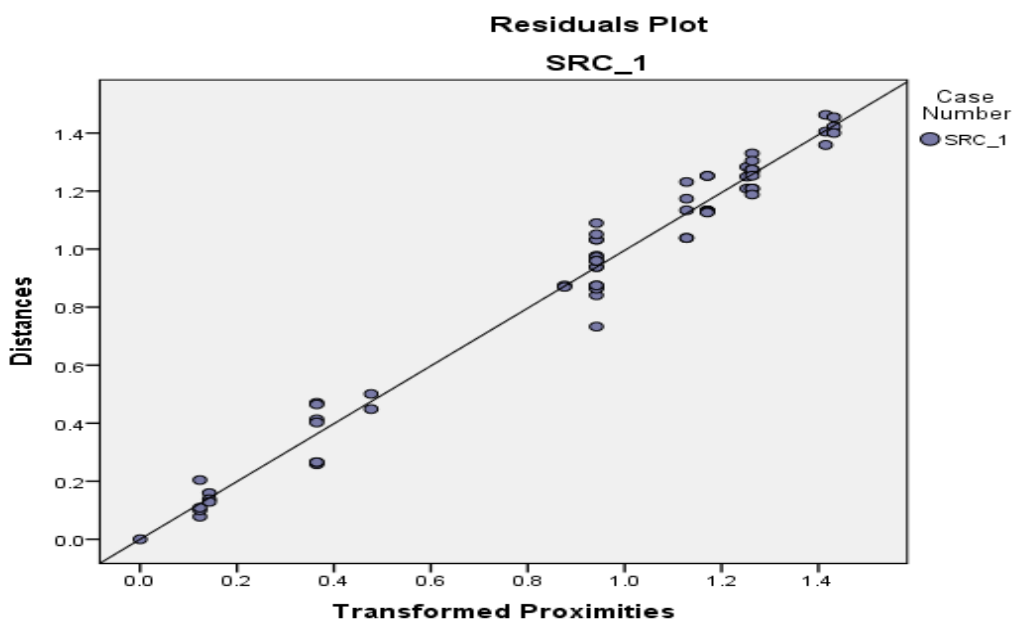

Figure 3a. Shepard's diagram for students' learning difficulties and their effort in understanding concepts

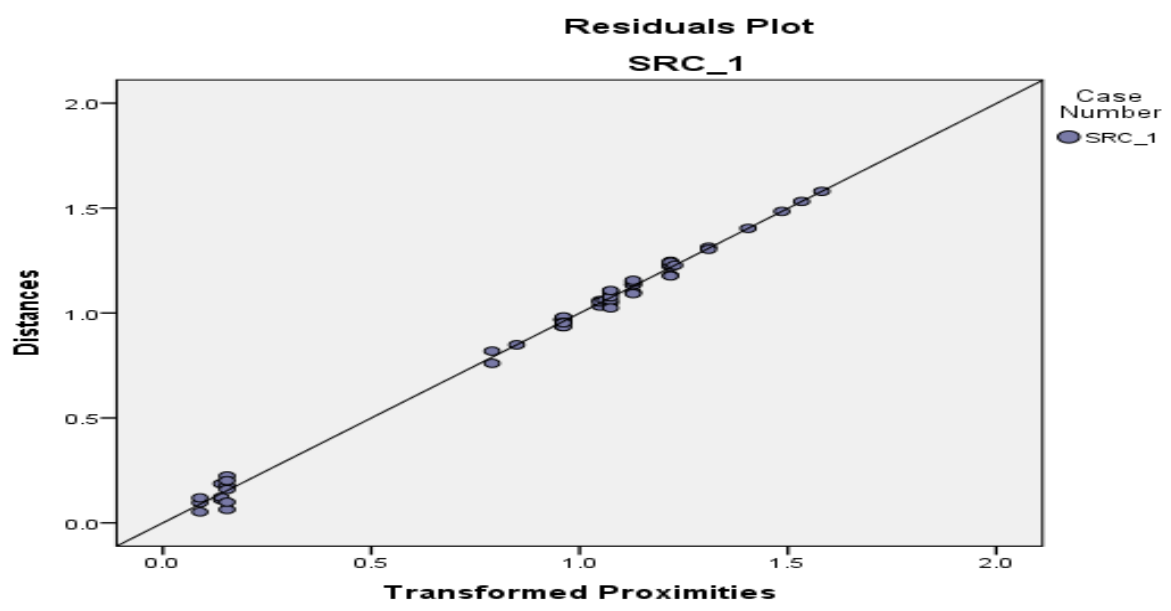

Figure 3b. Shepard's diagram for students' learning styles and preferences based on Kolb's Learning Model and their effort in understanding concepts

Fig. 3 (a-b) illustrates the Shepard's diagram between distances and transformed proximities for the MDS solutions. The data shows approximate straight-line relationship with minimal dispersion. This indicates that the original proximities are represented well as distances in a multidimensional space and can interpret the configuration of MDS solutions well. This is a good fit of the solution as indicated by the little amount of spread in the Shepard's diagram.

Table 6 and Table 7 show the distance between codes and items. The low value of distance provides the high similarity and the high value provides the high dissimilarity (Ding, 2006). Fig. 4 and Fig. 5 display the similarities or proximities maps between the items. 
Table 6: The distance between the reasons for the students' learning difficulties and their efforts in understanding concepts

\begin{tabular}{|c|c|c|c|c|c|c|c|c|c|c|c|c|}
\hline & Effort 1 & Effort 2 & Effort 3 & Effort 4 & Effort 5 & Effort 6 & Effort 7 & Able & Theo & Plnow & Att & Comp \\
\hline Effort 1 & .000 & & & & & & & & & & & \\
\hline Effort 2 & .875 & .000 & & & & & & & & & & \\
\hline Effort 3 & 1.400 & 1.033 & .000 & & & & & & & & & \\
\hline Effort 4 & 1.330 & 1.274 & .470 & .000 & & & & & & & & \\
\hline Effort 5 & .204 & 1.038 & 1.422 & 1.283 & .000 & & & & & & & \\
\hline Effort 6 & .875 & .000 & 1.033 & 1.274 & 1.038 & .000 & & & & & & \\
\hline Effort 7 & 1.253 & 1.209 & .465 & .078 & 1.209 & 1.209 & .000 & & & & & \\
\hline Able & 1.090 & .266 & .866 & 1.188 & 1.231 & .266 & 1.133 & .000 & & & & \\
\hline Theo & 1.455 & 1.133 & .109 & .403 & 1.463 & 1.133 & .413 & .973 & .000 & & & \\
\hline Pknow & .259 & .960 & 1.266 & 1.126 & .159 & .960 & 1.051 & 1.129 & 1.304 & .000 & & \\
\hline Att & .977 & 1.252 & .864 & .501 & .875 & 1.252 & .449 & 1.272 & .841 & .733 & .000 & \\
\hline Comp & .129 & .939 & 1.359 & 1.250 & .100 & .939 & 1.174 & 1.134 & 1.405 & .138 & .870 & .000 \\
\hline
\end{tabular}

Effort $1=$ Study in group, Effort 2 = Study on my own, Effort $3=$ Read notes, Effort $4=$ Read textbooks, Effort $5=$ Consult the lecturer, Effort $6=$ Do practice exercise, Effort $7=$ look up for other notes from the internet, ABLE = Ability, THEO=Theory, $\mathrm{PKNOW}=$ Prior Knowledge, $\mathrm{ATT}=$ Attitude, $\mathrm{COMP}=$ Computation

Table 7: The distance between the students' learning style preferences based on Kolb's Learning Model and their efforts in understanding concepts

\begin{tabular}{|c|c|c|c|c|c|c|c|c|c|c|c|}
\hline & Effort 1 & Effort 2 & Effort 3 & Effort 4 & Effort 5 & Effort 6 & Effort 7 & Assimilating & Converging & Diverging & Accommodating \\
\hline Effort 1 & .000 & & & & & & & & & & \\
\hline Effort 2 & 1.060 & .000 & & & & & & & & & \\
\hline Effort 3 & 1.580 & .967 & .000 & & & & & & & & \\
\hline Effort 4 & 1.181 & 1.242 & .818 & .000 & & & & & & & \\
\hline Effort 5 & .187 & 1.133 & 1.532 & 1.048 & .000 & & & & & & \\
\hline Effort 6 & 1.107 & .052 & .936 & 1.246 & 1.176 & .000 & & & & & \\
\hline Effort 7 & 1.220 & 1.227 & .760 & .064 & 1.093 & 1.229 & .000 & & & & \\
\hline Assimilating & 1.104 & 1.304 & .970 & .159 & .955 & 1.314 & .223 & .000 & & & \\
\hline Converging & 1.093 & .119 & .848 & 1.156 & 1.147 & .096 & 1.137 & 1.228 & .000 & & \\
\hline Diverging & .177 & .935 & 1.404 & 1.024 & .201 & .979 & 1.060 & .960 & .953 & .000 & \\
\hline Accommodating & .122 & 1.033 & 1.484 & 1.060 & .111 & 1.077 & 1.100 & .982 & 1.052 & .099 & .000 \\
\hline
\end{tabular}

Effort $1=$ Study in group, Effort $2=$ Study on my own, Effort $3=$ Read notes, Effort $4=$ Read textbooks, Effort $5=$ Consult the lecturer, Effort $6=$ Do practice exercise, Effort $7=$ look up for other notes from the internet

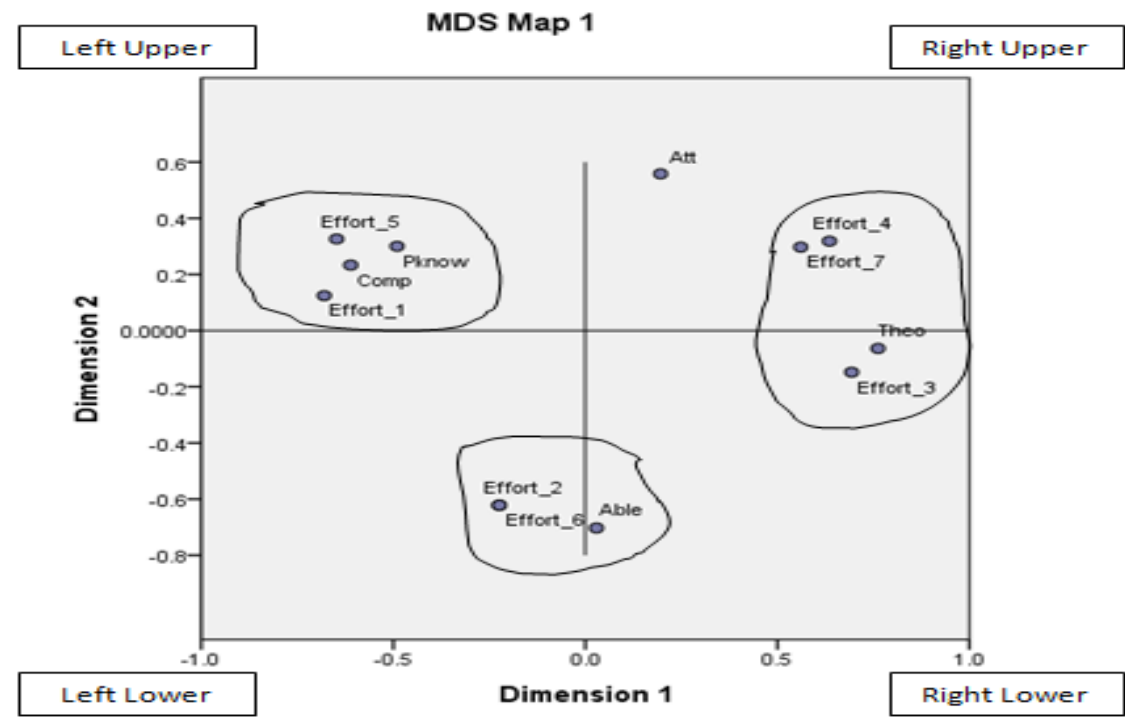

Figure 4. MDS 2-dimensional solution of the reasons for students' learning difficulties and their effort toward understanding topics

Fig. 4 shows that those who have prior knowledge in statistics (Pknow) can handle the computational exercises well (Comp). They also tend to consult the lecturer (Effort 5) and prefer to study in a group (Effort 
1). These themes are illustrated in the upper left quadrant of dimensions 1 and 2 where they are closer to one another. In the lower left quadrant of dimensions 1 and 2, students with high ability (Able) tend to work alone (Effort 2) and do practice exercises (Effort 6). In the upper right quadrant, it is observed that students who are able to understand theory (Theo) prefer to read notes (Effort 3) more than others. These items also tend to be closer to their efforts in reading textbooks (Effort 4) and looking up for other notes from the internet (Effort 7).

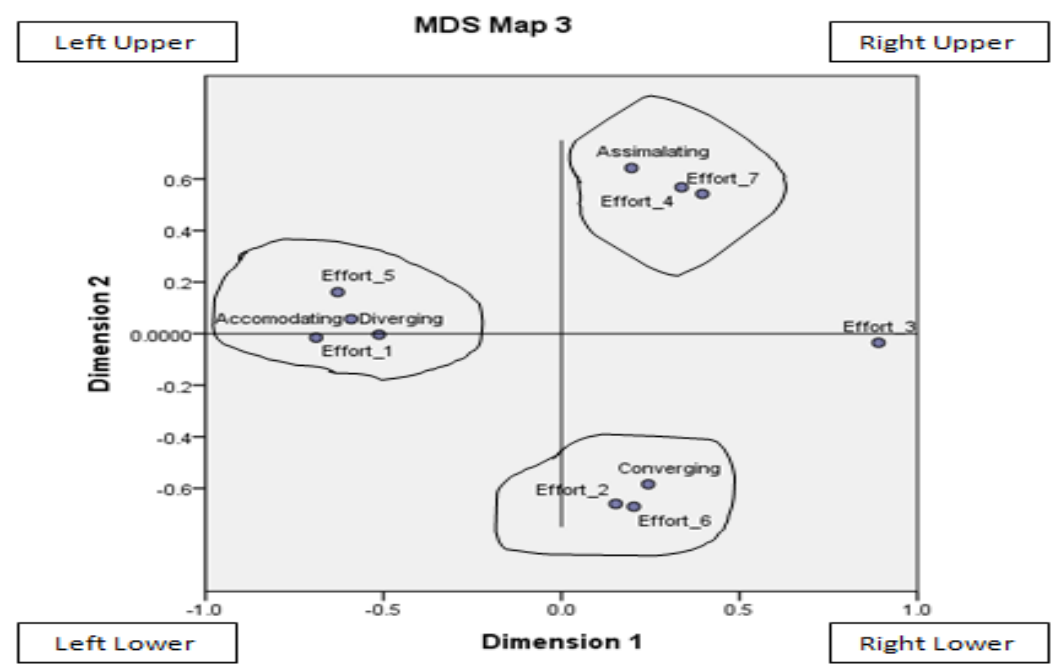

Figure 5. MDS 2-dimensional solution of students' learning styles and preferences based on Kolb's Learning Model and their effort in understanding topics

Fig. 5 shows that students in the "Diverging" and "Accommodating" groups tend to study in a group (Effort 1) and prefer to consult the lecturer, as illustrated in the upper left quadrant of dimensions 1 and 2 . In the lower right quadrant, those in the "Converging" group prefer to do practice exercises (Effort 6) and study on their own (Effort 2) while those in the 'Assimilating' group, prefer to read their textbooks and look up for other sources in the internet.

\section{CONCLUSION AND DISCUSSION}

This study concludes that students' difficulties in learning statistical topics are in some ways related to their learning styles and preferences. Generally, most of these difficulties can be overcome when both the students and instructors are aware of how different learning styles impact learning of statistics in different ways. Some students tend to search for convenience and comfort when learning statistics while others will employ strategies that will enhance their effective learning of statistics.

The use of Kolb's Learning Model has allowed this study to categorize students' learning styles and preferences into the four categories of 'Converging', 'Assimilating', 'Accommodating' and 'Diverging'. Regardless of which category they fall into, the students found that their learning styles are effective in helping them overcome difficulties in learning a range of statistical topics.

This study also classifies a big majority of the students into the 'Converging' category as they seemed to prefer doing practice exercises as well as study on their own in their effort to understand some of these statistical topics. On the other hand, students that are categorized in the 'Assimilating' group are more likely to read textbooks and look up for notes from other sources such as the internet. They would also prefer to meet their lecturers in an effort to seek a better understanding of the topics. Finally, students that are classified under the 'Accommodating' and 'Diverging' group will generally seek to understand statistical concepts by studying in a group and reading notes that are provided to them.

\section{REFERENCES}

Borg, I., Groenen, P. J., \& Mair, P. (2012). Applied multidimensional scaling. Springer.

Chapman, A. (2006). Diagrams of Kolb's Learning Styles. In Kolb learning styles. Retrieved from http://www.businessballs.com/kolblearningstyles.htm 
Christou, N. and Dinov, I. D. (2010). A Study of Students' Learning Style, Discipline Attitudes and Knowledge Acquisition in Technology-Enhanced Probability and Statistics Education. Merlot Journal of Online Learning and Teaching, 6(3), 546-572.

Creswell, J. W., Klassen, A. C., Clark, V. L. P. and Smith, K. C. (2010). Best Practices for Mixed Methods Research in the Health Sciences.

Ding, C. S. (2006). Multidimensional scaling modelling approach to latent profile analysis in psychological research. International Journal of Psychology, 41(3), 226-238.

Garfield, J. (1995). How Students Learn Statistics. International Statistical Review, 63(1), 25-34.

Garfield, J., \& Ben-Zvi, D. (2004). Research on statistical literacy, reasoning, and thinking: issues, challenges, and implications. In D. Ben-Zvi \& J.Garfield (Eds.), The Challenge of Developing Statistical Literacy, Reasoning, and Thinking (pp. 397-409). Dordrecht, The Netherlands: Kluwer Academic Publishers (Springer).

Hair, J., Black, B. Babin, B., Anderson, R. and Tatham, R. (2010). Multivariate Data Analysis (7th edition). Upper Saddle River, NJ: Prentice-Hall.

Johnson, R. A., \& Wichern, D. W. (2002). Applied multivariate statistical analysis. Upper Saddle River, NJ: Prentice Hall.

Kolb, D.A. (1984). Experiential learning: Experience as the source of learning and development. Englewood Cliffs: Prentice-Hall Inc.

Kruskal, J. B., \& Wish, M. (1978). Multidimensional scaling. Beverly Hills: Sage.

Miles, M. B., \& Huberman, A. M. (1994). Qualitative data analysis: An expanded sourcebook. Sage.

Ministry of Educations. (2006). Integrated Curriculum for Secondary Schools: Syllabus Additional Mathematics. Kuala Lumpur, Curriculum Development Centre.

Nooriafshar, M. (2003). Factors contributing to making the learning of statistics an enjoyable experience. International Journal for Mathematics Teaching and Learning, (May 14), 1-12.

Quinn, G. P., \& Keough, M. J. (2002). Experimental design and data analysis for biologists. Cambridge University Press.

Reid, G. (2005). Learning Style and Inclusion. London, Paul Chapman Publishing.

Robbin, S. (1998) Organization Behavior. NJ: Prentice Hall.

Romanelli, F., Bird, E. and Ryan, M. (2009). Learning Styles: A Review of Theory, Application, and Best Practices.

Schau, C., Millar, M., \& Petocz, P. (2012). Research On Attitudes Towards Statistics, Statistics Education Research Journal, 11(2), 2-5.

Seiler, D. (2011). Age and learning style in the adult learner. J. Hum. Res. Adult Learn, 7(2), 133-138.

Tanner, K. \& Allen, D. (2004) Approaches to biology teaching and learning: learning styles and the problem of instructional selection-engaging all students in science courses, Cell Biology Education, 3, pp.97201.

Tsai, C., \& Kuo, P., (2008). Cram School Students' Conceptions of Learning and Learning Science in Taiwan. International Journal of Science Education, 30 (3), 353-375.

Zamalia, M., and Rosli, A. R. (2009). " Visualizing patterns of interview conversations regarding students' learning difficulties in statistical concepts via QMD Scaling techniques. Wseas Transactions on Information Science and Applications.

Zamalia, M. and Nur Hasmaniza, O. (2010). Statistical competency and attitude towards learning elementary statistics: A case of SMK Bandar Baru Sg Buloh. In Proceedings of the Regional Conference on Statistical Sciences (pp. 335-348). 